Contributors: AP had the original idea for this study, which was then designed and planned by him and MP and NK. Initial assessment and optimisation of laboratory methods was undertaken by GD, DI, and MP, who subsequently collected and analysed the patient data. The paper was written by MP, NK, and $\mathrm{AP}$ with contributions from GD and DI. MP and NK are guarantors of this study.

1 Wise R, Hart T, Cars O, Streulens M, Helmuth R, Huovinen P, et al. Antimicrobial resistance. $B M J$ 1998;317:609-10.
2 Docke WD, Randow F, Syrbe U, Krausch D, Asadullah K, Reinke P, et al. Monocyte deactivation in septic patients: restoration by IFN-gamma treatment. Nat Med 1997;3:678-81.

3 Wilkinson JD, Pollack MM, Ruttimann UE, Glass NL, Yeh TS. Outcome of pediatric patients with multiple organ system failure. Crit Care Med 1986;14:271-4.

4 Asadullah K, Woiciechowsky C, Docke WD, Liebenthal C, Wauer H, Kox $\mathrm{W}$, et al. Immunodepression following neurosurgical procedures. Crit Care Med 1995;23:1976-83.

5 Schinkel C, Sendtner R, Zimmer S, Faist E. Functional analysis of monocyte subsets in surgical sepsis. J Trauma 1998;44:743-8.

(Accepted 5 March 1999

\title{
Ethnic differences in use of hormone replacement therapy: community based survey
}

\author{
Tess J Harris, Derek G Cook, Paul D Wicks, Francesco P Cappuccio
}

Department of General Practice and Primary Care, St George's

Hospital Medica School, London SW17 0RE

Tess J Harris lecturer

Department of Public Health

Sciences,

St George's

Hospital Medical

School

Derek G Cook

professor

Paul D Wicks

statistician

Blood Pressure Unit, Department of

Medicine,

St George's

Hospital Medical

School

Francesco P

Cappuccio

reader

Correspondence to: Professor Cook

d.cook@sghms.ac.uk

BMJ 1999;319:610-1
Hormone replacement therapy is widely promoted to prevent cardiovascular disease and osteoporosis and relieve menopausal symptoms, although concern exists that much of the cardiovascular effect may be due to its selection by healthy women. ${ }^{1}$ Little is known about its use by women from different ethnic groups in the United Kingdom, particularly women of south Asian origin, who are at increased risk of coronary heart disease, ${ }^{2}$ osteoporosis, ${ }^{3}$ and diabetes ${ }^{4}$ compared with white women.

\section{Subjects, methods, and results}

A population based survey was carried out in Wandsworth, south London, where roughly 12\% of residents are from the Caribbean or west Africa (that is, of African descent) and 6\% are of Indian, Pakistani, or Bangladeshi origin (that is, south Asian). Women aged 40-59 were invited from nine general practices as part of a cardiovascular screening study. ${ }^{4}$ The response rate was $66 \%(941 / 1429)$. Of the 941 women screened, 882 were from one of the ethnic groups being studied.

Ethnic group was recorded at interview on the basis of answers to several questions, including questions on country of birth, language, religion, history of migration, and parental country of birth. Women were asked to bring someone to translate if they could not speak English. This analysis is restricted to data recorded at the interview, as we were interested in factors in the history that could have influenced hormone prescribing. Proportions were compared with $\chi^{2}$ and Fisher's exact tests. The odds of current hormone use was modelled using logistic regression.

White ethnic group, hysterectomy, smoking, and greater age were associated with current hormone use and were included in the model to produce adjusted odds ratios (table). All except smoking remained independently associated with hormone use. Adjusting for practice made little difference to the estimated odds ratios for other variables (data not shown). Restricting analyses to women over 50 gave similar differences between ethnic groups.

Among white women those who had had a hysterectomy were twice as likely to be hormone users as those who had not $(54 \%(7 / 13)$ v 23\% (63/269), $\mathrm{P}=0.02)$. The difference was similar among women of
African descent $(32 \%(6 / 19)$ v 14\% (45/314), $\mathrm{P}=0.05)$ but was not seen among south Asian women (8\% $(1 / 12) v 10 \%(24 / 238), \mathrm{P}=1.0)$. Differences in the effect of hysterectomy between ethnic groups were not significant $(\mathrm{P}=0.44)$.

A greater proportion of women from the Caribbean than from Africa used hormone replacement $(19 \%(40 / 214)$ v $9 \%(10 / 107))$. Similarly, women of Pakistani origin were more likely to be users $(17 \%$ $(6 / 36))$ than women of Indian $(10 \%(18 / 185))$ or Bangladeshi origin $(3 \%(1 / 29))$. None of these differences, however, was significant at the $5 \%$ level. All of these rates were lower than the $25 \%$ found in white women.

\section{Comment}

Women from ethnic minority groups were less likely than white women to use hormone replacement therapy. The differences were independent of other factors, including smoking, age, and hysterectomy. As others have reported, ${ }^{5}$ women with cardiovascular disease were not more likely to be prescribed hormone replacement, although it is often advised. This suggests continuing uncertainty about risks and benefits.

Our study has potential limitations, including response bias. However, those who refused to take part were comparable to the population surveyed for all aspects considered. ${ }^{4}$ The prevalence of current hormone use in white women that we found is similar to other recent work in the United Kingdom, ${ }^{5}$ lending validity to our findings.

The differences in use of hormone replacement reported here have not to our knowledge been described before in the United Kingdom. They are important, because possible long term protective effects on heart and bone may particularly benefit south Asian women. Uptake of other preventive health measures is lower in south Asian than white or African-Caribbean women in the United Kingdom.

Hormone replacement assessment provides an opportunity for health promotion, assessing cardiovascular risk factors, and discussing cervical and breast screening. Opportunities for these discussions with women from ethnic minority groups may be being missed. Further research is needed, particularly among 
Association between characteristics of women and current use of hormone replacement therapy (HRT), with both crude and adjusted odds ratios

\begin{tabular}{|c|c|c|c|c|}
\hline & \multirow{2}{*}{$\begin{array}{l}\text { Total No of women } \\
\quad(n=865)^{*}\end{array}$} & \multirow{2}{*}{$\begin{array}{l}\text { No (\%) of women } \\
\text { using HRT }\end{array}$} & \multicolumn{2}{|c|}{ Odds ratio $(95 \% \mathrm{Cl})$} \\
\hline & & & Crude & Adjusted $\dagger$ \\
\hline \multicolumn{5}{|l|}{ Ethnic group: } \\
\hline White & 282 & $70(24.8)$ & 1 & 1 \\
\hline African descent & 333 & $51(15.3)$ & 0.55 (0.36 to 0.83$)$ & 0.54 (0.35 to 0.83$)$ \\
\hline South Asian & 250 & $25(10.0)$ & 0.32 (0.19 to 0.53$)$ & 0.37 (0.22 to 0.63$)$ \\
\hline \multicolumn{5}{|l|}{ Hysterectomył: } \\
\hline No & 821 & $132(16.1)$ & 1 & 1 \\
\hline Yes & 44 & $14(31.8)$ & 2.44 (1.19 to 4.92$)$ & 2.55 (1.28 to 5.10$)$ \\
\hline \multicolumn{5}{|l|}{ Current smoker: } \\
\hline No & 738 & $113(15.3)$ & 1 & 1 \\
\hline Yes & 126 & $33(26.2)$ & 1.96 (1.23 to 3.13$)$ & 1.59 (0.97 to 2.60$)$ \\
\hline \multicolumn{5}{|l|}{ Age (years): } \\
\hline$<45$ & 206 & $15(7.3)$ & 1 & 1 \\
\hline $45-49$ & 219 & $35(16.0)$ & 2.42 (1.23 to 4.82$)$ & 2.64 (1.38 to 5.06$)$ \\
\hline $50-54$ & 225 & $49(21.8)$ & 3.55 (1.85 to 6.87$)$ & 3.74 (2.00 to 7.00$)$ \\
\hline$\geqslant 55$ & 215 & $47(21.9)$ & 3.56 (1.85 to 6.93$)$ & 4.02 (2.14 to 7.56$)$ \\
\hline \multicolumn{5}{|l|}{ Hypertensionł: } \\
\hline No & 568 & $93(16.4)$ & 1 & 1 \\
\hline Yes & 295 & $53(18.0)$ & $1.12(0.76$ to 1.65$)$ & 1.09 (0.73 to 1.64$)$ \\
\hline \multicolumn{5}{|l|}{ Diabetes mellitus‡: } \\
\hline No & 799 & $138(17.3)$ & 1 & 1 \\
\hline Yes & 65 & $8(12.3)$ & $0.67(0.29$ to 1.50$)$ & 0.69 (0.31 to 1.53$)$ \\
\hline \multicolumn{5}{|l|}{ High cholesterolł: } \\
\hline No & 792 & $128(16.2)$ & 1 & 1 \\
\hline Yes & 69 & $17(24.6)$ & 1.70 (0.91 to 3.13$)$ & 1.44 (0.78 to 2.65$)$ \\
\hline \multicolumn{5}{|c|}{ Ischaemic heart diseaseł: } \\
\hline No & 836 & $138(16.5)$ & 1 & 1 \\
\hline Yes & 29 & $8(27.6)$ & $1.93(0.77$ to 4.70$)$ & 1.40 (0.58 to 3.34$)$ \\
\hline \multicolumn{5}{|l|}{ Cardiovascular risk§: } \\
\hline No & 507 & 79 (15.6) & 1 & 1 \\
\hline Yes & 358 & $67(18.7)$ & 1.25 (0.86 to 1.81$)$ & 1.17 (0.79 to 1.72$)$ \\
\hline \multicolumn{5}{|l|}{ Social classf: } \\
\hline I and II & 273 & $47(17.2)$ & 1 & 1 \\
\hline IIINM and IIIM & 359 & $65(18.1)$ & 1.06 (0.69 to 1.64$)$ & 0.86 (0.56 to 1.33$)$ \\
\hline IV and V & 171 & $27(15.8)$ & $0.90(0.52$ to 1.56$)$ & 0.70 (0.41 to 1.22$)$ \\
\hline \multicolumn{5}{|c|}{ Age on leaving full time education (years): } \\
\hline$\leqslant 15$ & 210 & $45(21.4)$ & 1 & 1 \\
\hline $16-19$ & 441 & $76(17.2)$ & 0.76 (0.50 to 1.18$)$ & 1.06 (0.68 to 1.65$)$ \\
\hline$>19$ & 200 & $23(11.5)$ & $0.48(0.27$ to 0.85$)$ & 0.87 (0.48 to 1.57$)$ \\
\hline
\end{tabular}

${ }^{*} 17$ women with contraindications to HRT were excluded (thromboembolic disorder; breast, endometrial, and ovarian cancer; liver disease), leaving 865 subjects. Numbers sometimes add up to less than 865 because of missing values.

†For ethnic group, hysterectomy, smoking, and age.

fFrom woman's history.

$\S$ Woman had history of one or more of hypertension, diabetes, high cholesterol concentration, or ischaemic heart disease.

ISocial class was classified according to partner's occupation, or by the woman's if she had no partner.

south Asian women, to explore reasons for the differences in hormone use observed.

We thank the participating general practitioners for their cooperation and help in allowing access to their registers and patients, the staff in the Blood Pressure Unit and in the Department of Public Health sciences for their technical support, and the women for participating in the study. FPC and DGC are members of the St George's Cardiovascular Research Group PDW is also a member of the Blood Pressure Unit.

Contributors: DGC and FPC set up the Wandsworth heart and stroke study and were responsible for data collection. TH, DGC, and FPC developed the idea of looking at use of hormone replacement therapy. TH was responsible for drafting and editing the paper. PW, TH, and DGC analysed and interpreted the data. All authors participated in revising the manuscript and approving the final version. TH and DGC are guarantors of the paper.

Funding: The Wandsworth heart and stroke study has received funding from Wandsworth Health Authority, South West Thames Regional Health Authority, the NHS Research and Development Directorate, the British Heart Foundation, the British Diabetic Association, and the Stroke Association.

Competing interests: None declared.
1 Barrett-Connor E. Hormone replacement therapy. BMJ 1998;317 $457-61$.

2 Balarajan R. Ethnic differences in mortality from ischaemic heart disease and cerebrovascular disease in England and Wales. BMJ 1991:302:560-4

3 Tobias JH, Cook DG, Chambers TJ, Dalzell N. A comparison of bone mineral density between Caucasian, Asian and Afro-Caribbean women. mineral density between

4 Cappuccio FP, Cook DG, Atkinson RW, Strazzullo P. Prevalence, detection, and management of cardiovascular risk factors in different ethnic groups in South London. Heart 1997;78:555-63.

5 Griffiths F, Jones K. The use of hormone replacement therapy; results of a community survey. Fam Pract 1995;12:163-5.

(Accepted 20 May 1999)

\section{Endpiece \\ The grind is the thing}

There is no human bliss equal to 12 hours of work with only six hours in which to do it.

Anthony Trollope, Orley Farm 